Y. TANAKA, S. SAITO, S. MORI, N. ARATANI, H. SHINOKUBO, N. SHIBATA, Y. HIGUCHI, Z. S. YOON, K. S. KIM, S. B. NOH, J. K. PARK, D. KIM,* A. OSUKA* (YONSEI UNIVERSITY, SEOUL, KOREA; KYOTO UNIVERSITY, UNIVERSITY OF HYOGO AND THE RIKEN SPRING- 8 CENTER, HYOGO, JAPAN)

Metalation of Expanded Porphyrins: A Chemical Trigger Used To Produce Molecular Twisting and Möbius Aromaticity

Angew. Chem. Int. Ed. 2008, 47, 681-684.

\title{
Metalation-Triggered Möbius Aromaticity
}
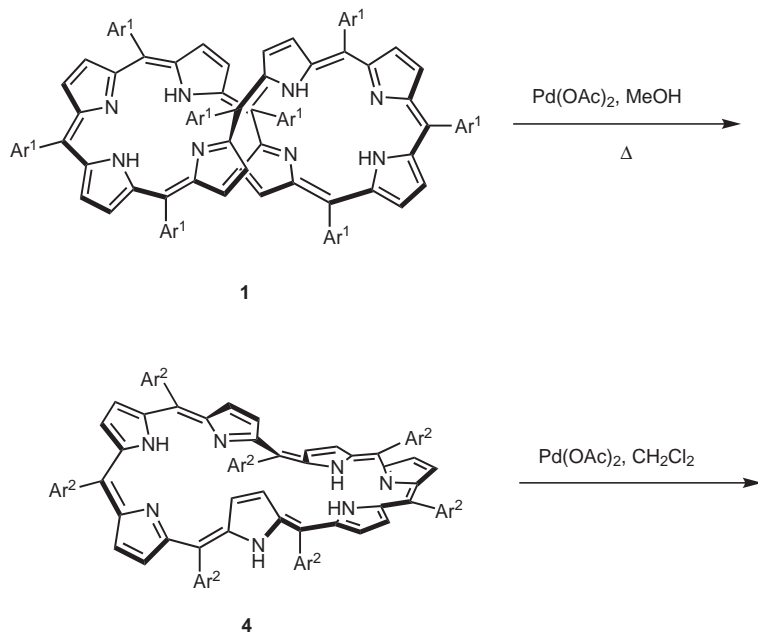

$\mathrm{Pd}(\mathrm{OAc})_{2}, \mathrm{CH}_{2} \mathrm{Cl}_{2}$

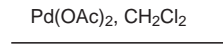

\section{Gategory}

Synthesis of Materials and Unnatural Products

\section{Key words}

Möbius aromaticity

expanded porphyrins

metalation templating

two-photon absorption

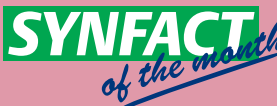

Significance: A new way to achieve complexes that exhibit Möbius aromaticity is described. Conjugated oligopyrrolic macrocycles (also known as expanded porphyrins) were locked into a twisted Möbius strip conformation using group 10 metals. Experimental and numerical studies reveal compounds 3, 5, and 7-9 as conformationally locked Möbius aromatic molecules.
Comment: Structures and aromaticity were confirmed via XRD $(\mathbf{2}, \mathbf{3}, \mathbf{5}),{ }^{1} \mathrm{H}-\mathrm{NMR}$ and UV/Vis. Significantly negative values of calculated NICS (Nucleus-Independent Chemical Shift) supported Möbius-type aromaticity for 3, 5, and 7-9. A new method for the quantitative analysis of aromaticity based on the measurement of the TPA (two-photon absorption) cross-section $\left(\sigma^{(2)}\right)$ by the openaperture Z-scan method showed consistent results.

sYNFACTS Contributors: Timothy M. Swager, Jose M. Lobez DoI: 10.1055/s-2008-1042849; Reg-No.: S01508SF 